\title{
Recollection
}

\section{Xiangtong Zhang's study on dendritic function: Gold is shining everywhere}

\author{
Baoyuan Zhang, Le Kang \\ Beijing Institutes of Life Science, Chinese Academy of Sciences, Beijing 100101, China
}

It was in 1900, 16 years after Gregor Johann Mendel's death, that Mendel's laws were widely accepted and the significance was well acknowledged by the scientific world. Similarly, it was in 1983, 30 years after Barbara McClintock's innovative discoveries, that she won an unshared Nobel Prize in Physiology or Medicine for the theory of jumping genes. Those touching stories have been talked a lot in scientific field, and those outstanding biologists have been memorized for their advanced theories, their persistence and their legacies. History always repeats itself. The neurophysiologist Xiangtong Zhang (Hsiang-tung Chang) also had a same experience, while he was rarely recognized by people.

Xiangtong Zhang, Academician of Chinese Academy of Sciences (CAS), was one of the founders for neuroscience research in China and for the establishment of Shanghai Brain Research Institute. His pioneer work on the physiological function of dendrites has been well-acknowledged by worldwide scientists. He was elected Foreign Honorary Academician of the Royal Academy of Medicine of Belgium, Member of the Central Committee of International Brain Research Organization, and Neurological Consultant of the World Health Organization.

In the winter of 1992, Xiangtong Zhang received a surprising letter, which informed that he would be honored with "Life Achievement Award" from the International Neural Network Society, and he was invited to the award ceremony. At first, he thought it must be a mistake by the Society because the Society was organized by engineers in computer studies, while he was neither an engineer nor a computer scientist. However, only after reading the letter did he realize that all the things were closely related to his study on nervous dendrites over 40 years ago. The certificate of commendation especially noted that he is the first to recognize the functional significance of dendrites in central nervous system, which was one of the important symbols for developing new generation computer, and his remarkable achievement laid the theoretic foundation for the application

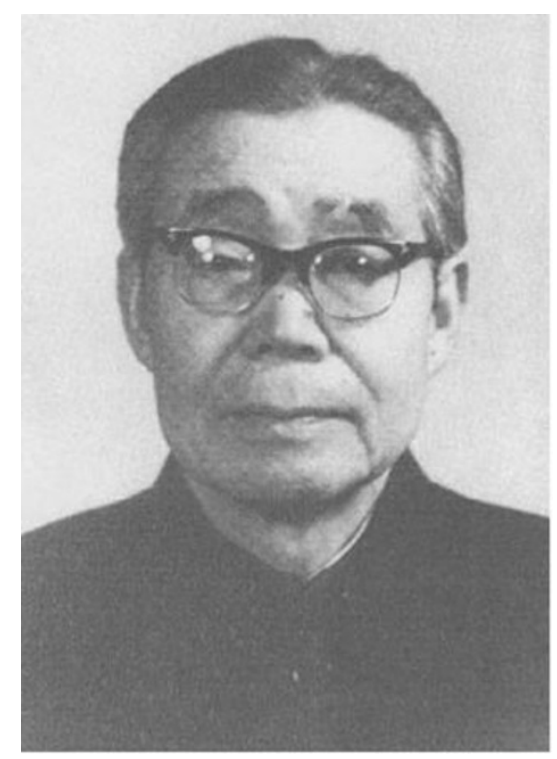

\section{Dr. Xiangtong Zhang}

of neural network computer instead of electronic digital computer.

In the middle period of 20th century, many neurophysiologists had clearly realized that axon was one protoplasmic protrusion, carrying nerve impulses away from the cell body of neuron. But few realized that the dendrites were also able to conduct nerve impulses. From 1950 to 1955, Xiangtong Zhang devoted all his time to the study of dendrites. As an Associate Researcher at Rockefeller Institute for Medical Research, he investigated the functional characteristics of apical dendrites of pyramidal neurons in the cerebral cortex using an electrophysiological approach, and his nine publications on dendrites function had widespread influence in the neurophysiological field. After he returned to China in 1956, he continued his research on nervous system with great enthusiasm. With six years of arduous efforts, he built 


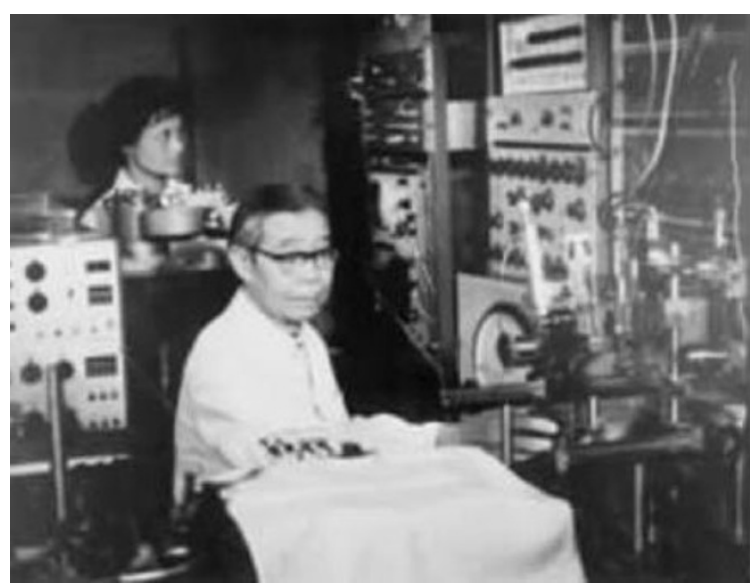

Dr. Xiangtong Zhang in his laboratory

up the first laboratory to study nerve cells in China. Many outstanding Chinese neurophysiologists were trained in his laboratory, including Academician Jiangping Wu, Academician Yizhang Chen, et al. For his brilliant contribution in neuroscience, he was regarded as one of the pioneers in the study of dendritic potentials and the first to purpose a fundamental distinction between axosomatic and axodendritic synapses. However, it was beyond his imagination that his research results were actually conducive to the development of intelligent computer.

Although the award was a big surprise, Xiangtong Zhang thought he did not have a lot to show off. In his mind, it was a slight incident on his tortuous path of brain research. He treated it as a quiet coming and a silent leaving, with no celebration, no pride, and even no one knowing it. He carefully summarized his experience, and pointed out that the social significance and the practical value of basic theory is often not recognized soon after its formation; instead, its light will radiate when social sciences and other related branch sciences reach the corresponding level.

Maybe some people would describe Xiangtong Zhang's prize as chance and serendipity. However, when we review his life, he really deserves this prestigious award. During the long years, from beginning to end, he focused his attention on the neurophysiological research to uncover the mysteries of nervous system. Even when encountering serious obstacles and enduring painful difficulties, he never gave up his research. His hypothesis that dendrites were able to conduct action potentials, in spite of controversies and objections in the past 40 years, was finally proven to be correct. God helps those who help themselves, and strong-willed men could change their fate in adversity. Just like what Xiangtong Zhang said: "Life is colorful; I could still learn a lot from it. My strong survival ability, much like the cactus, would hold on and thrive in any difficult circumstance whether it is the desert or the thorns." His particular experience emphasized again on the important inspiration: science is a long-term and systematic research, and would not be accomplished in a short time; in no case should we pursue immediate successes or shortterm gains.

"Leave a trace wherever you go, like the cuttlefish" is Xiangtong Zhang's life-long motto. With his dedication to academic research, he has left us absolutely much more than a trace. His diligence and persistence will be engraved on our minds forever. Nowadays, with the development of life science, biologists not only have tremendous opportunities, but also face complex challenges. The secret of success in life is to be ready for the opportunity when it comes. Thus, it is important to be industrious, and it is more important to be patient and to be ready. After all, a rolling stone gathers no moss, and gold is shining everywhere. Only when great systematic work gather together, will life science be able to have a brilliant future.

\section{REFERENCES}

Zhang, W. (2003). Xiangtong Zhang. Shanghai, Shanghai SciTech Education Press. (张维. (2003). 张香桐传. 上海, 上海科技教育出 版社.)

Zhang, X. (1885). The road of brain research. Beijing, Scientific and Technological Literature Publishing House. (张香桐. (1995). 脑研 究的崎岖道路. 北京, 科学技术文献出版社.) 